\title{
Assessing Engineering Ethics Training
}

Ms. Melodie A. Selby PE, Walla Walla University

Melodie Selby is a civil engineering and environmental science assistant professor at Walla Walla University. A Walla Walla University graduate, she returned to the University in 2009 after 23 years during which she received a master's degree in environmental engineering, worked as a civil and environmental engineering consultant, and worked in the Nuclear Waste Program and Water Quality Program for the Washington State Department of Ecology. 


\section{Assessing Engineering Ethics Training}

All engineering schools accredited by $\mathrm{ABET}^{\mathrm{a}}$ are required to ensure their graduates have "an understanding of professional and ethical responsibility." To many ABET-accredited engineering schools, it is not clear whether they are meeting this requirement ${ }^{2}$. Walla Walla University (the University) is also struggling with this question. This describes the first efforts at assessing the engineering ethics training at the University. This information will help the faculty at the Edward F. Cross School of Engineering (School of Engineering) at the University continue to improve the ethics training of their engineering students. It will also increase the understanding of the validity of the chosen instrument by increasing the number of students who have taken the test. It may form the basis for future investigations into the differences between faith-based and secular engineering education in the area of engineering ethics.

\section{Statement of the Problem}

As a faith-based university, the University values a strong ethical approach to engineering. The University uses a comprehensive approach to teaching engineering ethics by including aspects of engineering ethics in a number of classes, rather than requiring a stand-alone engineering ethics course. Students are also required to complete religion courses equivalent to one four-credit class per year. However, the University has not had a systematic approach to assessing the ability of their students to understand ethical dilemmas and responsibility. Faculty are considering changes to the training in engineering ethics. Without an assessment of current student outcomes, changes would be based on anecdotal evidence only. The University needs to know the current level of understanding of engineering ethics in both freshmen and graduating seniors in order to appropriately revise the training we provide to our students. The University also needs to identify an appropriate assessment method for incoming freshmen so that faculty can adjust training as appropriate in real-time.

\section{Literature Review}

In 1996, ABET significantly revised their accreditation criteria for accreditations beginning in 2000, moving from prescriptive criteria to outcome-based criteria. ${ }^{3}$ One required student outcome of the revised criteria is " $3 \mathrm{f}$ : an understanding of professional and ethical responsibility." This is one of the so-called "professional skills." Teaching and assessing those skills has been a challenge for colleges and universities. Articles with titles such as "The ABET 'Professional Skills' - Can They Be Taught? Can They Be Assessed?"3 show the concerns that faculty expressed. There are three main questions that faculty struggle with and that researchers are attempting to answer. First, what is the goal in teaching engineering ethics? Second, what methods are effective in teaching engineering ethics? Finally, how can we assess student understanding of engineering ethics? This literature review will cover each of these questions.

\footnotetext{
a Formerly known as Accreditation Board for Engineering and Technology (ABET). In 2005, ABET formally changed its name to ABET and no longer uses the title "Accreditation Board for Engineering and Technology." http://www.abet.org.
} 


\section{Goals of Engineering Ethics Education}

The question of ethics in engineering education has always been considered of key importance. At the founding meeting of the American Society for Engineering Education (ASEE) in 1893, William H. Burr stated "The first and fundamental requisite in the ideal education of young engineers, a broad, liberal education in philosophy and the arts, is a precedent to the purely professional training"3 . Throughout the $20^{\text {th }}$ century, the role of ethics in engineering was debated and evolved. In the United States, engineering societies began adopting codes of ethics in the early $20^{\text {th }}$ century. Early codes focused primarily on business relationships, with later codes adding the concepts of responsibility to public safety and welfare and sometimes environmental protection. ${ }^{4}$ As ethics codes were modified, so was the teaching of engineering ethics. As additional science and math requirements were added to the engineering curriculum, the liberal arts foundation was reduced. By 1999, an ethics-related course requirement was included in only $27 \%$ of ABET-accredited engineering schools ${ }^{5}$. In his survey, Stephan included religion classes as ethics-related courses, so the number of institutions that required a specific engineering ethics course was lower still.

As the new ABET criteria $3 \mathrm{f}$ was instituted, faculty began attempting to clarify the goal of teaching engineering ethics. Sarah K. A. Pfatteicher, in an influential article, argued that "the criterion does not require programs to demonstrate that graduates are ethical; it requires that they understand professional and ethical responsibilities" (p. 137). ${ }^{6}$ As of July 2013, her article has been cited 31 times, according to Google Scholar, and her framing seems to be generally accepted. As Davis and Feinerman assert:

There is, of course, no way for ordinary academic methods to tell whether students will later use what they learned... But that is no surprise. Even in calculus, organic chemistry, and macro-economics, there is no test to tell whether students will use what they learn. The working assumption, derived from common sense, is that students are significantly more like to use what they know than what they do not know. We should not expect more of ethics assessment than of assessment in other subjects (p. 353). ${ }^{7}$

The codes of ethics of the various engineering societies are an obvious starting point in engineering ethics education. However, they are not sufficient to train students in recognizing and resolving ethical dilemmas. ${ }^{4,8}$ A number of approaches have been proposed by various authors. These include Chang and Wang's recommendation to combine cross-cultural understanding and engineering ethics to strengthen students' ability to systematically analyze situations from a variety of perspectives, ${ }^{9}$ as well as Bero and Kuhlman's recommendation to use the engineering design process as a model for solving ethical questions. ${ }^{10}$ Colby and Sullivan recommend that educators include the "macro ethics" issues of the engineer's responsibility to the public as a whole, not just their clients or the profession. ${ }^{8}$ Shuman, Sindelar, BesterfieldSacre, Wolfe, \& Pinkus recommend that we focus on students' ability to recognize and resolve ethical dilemmas. ${ }^{11}$

Although it may seem that there is no consensus on the goals of teaching engineering ethics, there is a broad theme, which Abaté describes as "training in the systematic, analytic and 
thoughtful evaluation of applied normative issues for professional practices" (p. 587) which leads to the ultimate aim "to instill careful clarity of insight and cogent decision-making skills" (p. 588). ${ }^{12}$

\section{Methods of Teaching}

In recent years, several studies have examined the way that institutions deliver ethics instruction. Li and Fu make a useful distinction between delivery methods, defined as the way the training is incorporated into the curriculum, and instructional strategy, defined as the way that instruction is delivered in a specific course. They found three primary delivery methods: embedded approach (also known as across the curriculum), joint model or team teaching approach, and a standalone course. ${ }^{13}$ Colby and Sullivan found similar delivery methods described as standalone ethics classes, brief discussions in multiple classes, and modules in introductory and/or capstone courses. Colby and Sullivan reviewed 100 ABET self-studies and visited 7 programs. They found that a carefully thought-out strategy for ethical instruction for engineering students was rare. Rather, "overall, a picture emerged of rather spotty and unsystematic attention to students' development of professional responsibility or ethics" (p. 332). ${ }^{8}$

When it comes to instructional strategy, the use of case studies was found by several researchers to be the most common method. ${ }^{3,4,8,13,14}$ Community based or service education is another method that is gaining in popularity. ${ }^{8}$ Simply teaching the codes of ethics is becoming less common. ${ }^{8}$ Individual instructors also use many other methods. ${ }^{13}$ The effectiveness of the various methods of teaching engineering ethics is a matter of debate because there is not a recognized method of assessing student outcomes related to engineering ethics. Researchers are beginning to develop methods to assess engineering ethics student outcomes.

\section{Assessment of Student Outcomes}

The challenges in assessing student outcomes in the professional skills have been widely noted. ${ }^{7,8,11,15}$ In assessing any learning outcome, the first step is to determine exactly what should be taught. As described above, the engineering profession is beginning to develop a consensus on what engineering students need to learn in the field of engineering ethics. Researchers are turning their attention to developing assessment methodology for student outcomes. Common issues in assessing student outcomes in engineering ethics include the fact of multiple acceptable answers, ${ }^{8,10}$ the time consuming nature of assessments, ${ }^{7}$ and the lack of comparable data from previous students or other institutions. ${ }^{7,10}$

Multiple acceptable answers do not preclude critical assessment, although many instructors simply assign pass/fail grades to ethics assignments because they "perceive the work involved in ethics modules and courses as essentially subjective and personal" (p. 333). ${ }^{8}$ However, as both Colby \& Sullivan and Bero \& Kuhlman point out, engineering professors are adept at assessing engineering designs which also have multiple acceptable answers. ${ }^{8,10}$ This does not imply that there are no wrong answers or that all acceptable answers are equally good. In evaluating designs, engineering professors judge how well the student understood and framed the problem, how well multiple criteria are met, how well the criteria are balanced against each other and how 
creative the solution is. A similar approach can be used in assessing solutions to ethical case studies and dilemmas. However, this approach to grading can be time-consuming.

Davis and Feinerman demonstrated the real-world difficulties caused by the timeconsuming nature of many assessments. They designed a study to "integrate ethics into graduate engineering classes at three universities - and to assess success in a way allowing comparison across classes (and institutions)" (p. 351). However, all the professors in the study rejected the use of the proposed assessment method. The assessment tool would have taken a total of 4 hours of class time for a pre- and post-test. For many classes, this would be approximately a twelfth of the total class time for the term. The researchers were forced to agree with the professors that was an inappropriate use of time in design classes. An interesting point raised by the professors in this study is the appropriateness of the assessment method depends on the class and its role in the curriculum. In a course aimed primarily at teaching ethics or professional skills, a significant assessment exercise may be appropriate. However, in embedding ethics instruction in design classes (as Davis and Feinerman were proposing), a more efficient assessment method is called for. Interestingly, there was consensus among the professors that 15 minutes at the beginning and end of the course would be an appropriate amount of time for ethics instruction embedded in a design course (p. 356). ${ }^{7}$

Barry \& Ohland describe a number of methods researchers have used to assess student outcomes in engineering ethics. One obvious contender is the ethics portion of the Fundamentals of Engineering exam, which is the major field exam for engineering. This exam has potential for useful research, but since it is only taken by seniors and many of the details of the exam are not released to researchers, Barry and Ohland conclude it is of limited use. ${ }^{2}$

A commonly used assessment of moral judgment is the Defining Issue Test. The test is based on Kohlberg's 3 levels of moral reasoning: preconventional, conventional and postconventional. The most recent version, the DIT-2, is used by a number of disciplines to assess moral judgment. ${ }^{4}$ Students are asked to evaluate 5 moral dilemmas. For each dilemma, students first choose what should be done. Then they assess 12 statements about the dilemma using the Likert scale from "great importance" to "no importance" and finally rank the 4 most important issues. The statements are designed to determine the maturity of the student's thinking about ethical issues. ${ }^{16}$ The $\mathrm{P}$ score from the assessment, which measures the degree to which postconventional thinking is present, is the score most used. The DIT-2 is popular because it is easy to use and score and it has been shown to be both valid and reliable. It takes approximately an hour to administer and because of its wide-spread use, there is a large body of knowledge regarding its use. ${ }^{4}$ However, it is a general test and does not assess discipline-specific issues. ${ }^{16}$

There have been several attempts to develop engineering-specific tests to assess moral judgment. At conferences in 2003 and 2004, initial results of a study to develop a test were reported. ${ }^{11,15}$ The reports seemed promising, but Barry and Ohland reported that the principal investigators were no longer working on the project and had no immediate plans to resume the study (p. 384). ${ }^{4}$

Davis and Feinerman developed a method of comparing ratios of pre- and post-tests developed by the instructor. This method allows instructors to customize their tests, but still 
allows for some comparison between classes. Their approach showed some promise, but will require more work to determine its validity. ${ }^{7}$

Borenstein et al. have developed an ESIT to serve as a discipline-specific assessment of moral judgment. This test shows promise but requires more use to further assess validity. It is similar to the DIT-2 and shares a common theoretical basis. They are encouraging other researchers to use the test in order to increase the data set. ${ }^{16}$ Of the current attempts to develop an assessment tool, the ESIT seems to be the only one still under development and the most promising for this study.

The latest ESIT survey instrument and scoring information was provided by the School of Public Policy, Georgia Institute of Technology. The sample sizes reported to date are too small to complete a comprehensive validity analysis on ESIT. However, the team did conduct a preliminary validity check. They reasoned that those who had prior ethics instruction should score higher on the ESIT. They reported:

Two-sample t-tests conducted on the post-test P and N2 scores identified significant differences at the $10 \%$ level between the average N2 scores of those students with prior ethics experience and those with no experience; there was no such significant difference evident for the P score. ... This provides some support for the validity and reliability of the ESIT instrument (Borenstein et al., 2010). ${ }^{16}$

\section{Methodology}

This study was designed as a first phase to study the effectiveness of teaching engineering ethics at the University. Later areas of study will build on this study and may include a longitudinal study and expansion to other institutions.

\section{Design}

This study was a non-experimental between-subjects non-equivalent groups design. This study was designed to compare the moral judgment of engineering students who are just beginning their studies at the University with those who are completing their studies. The study design was approved by the University's Ethics in Research Committee (EIRC).

\section{Hypothesis}

The University's teaching of engineering ethics increases students' engineering moral judgment as reflected in scores on the Engineering and Science Issues Test (ESIT), an engineering-specific assessment of moral judgment. If our hypothesis is correct, we would expect to see a statistically significant improvement in scores between the freshman and senior classes. 


\section{Materials/Instrumentation}

The ESIT survey instrument provided by the School of Public Policy, Georgia Institute of Technology was used in this study. An informed consent form was developed and the demographic information sheet adapted. An alternate ethics assignment was developed to give students who chose not to participate an alternative way of earning points.

\section{Participants}

Two groups of students were chosen to participate in this study. The first group was students enrolled in Introduction to Engineering (Intro) and the second group was students enrolled in Engineering Senior Seminar (ESS).

Students in Intro are students who have chosen to enroll in engineering at the University. Most of them are freshmen in their first quarter at the university. However, there are some transfer students or students who have chosen to switch to engineering after starting another major. All engineering students in ABET-accredited courses are required to complete this class, so it constitutes the entire population of entering students. At the instruction of the EIRC, students under the age of 18 were barred from participating in the study.

Students in ESS are seniors who are typically in their last year at the University. Senior status is required to take the class, so students will be near the end of their time at the University. All engineering students in ABET-accredited courses are required to complete this class as well as bioengineering students, so it constitutes the entire population of graduating students with the addition of bioengineering students. (Bioengineering is a joint offering by the School of Engineering and the School of Biology and is not an ABET-accredited program.)

\section{Procedure}

Students were provided with an informed consent form and requested to complete the ESIT as a class assignment. An alternate assignment was provided for students who did not wish to participate in the study or who were under the age of 18 at the time of the assignment. The alternate assignment was designed to take approximately the same amount of time as the ESIT and covered engineering ethics.

The instructions were given in class, then the ESIT and informed consent forms were distributed to be completed as a take-home assignment. The responses were collected by the instructors and returned to the researcher. The class assignment were graded as pass/fail with a completed ESIT or alternate assignment receiving a passing score, while an incomplete or not returned assignment received a 0 .

The instrument was administered twice to each class - once in the 2013-14 school year and once in the 2104-15 school year. 
Demographic information consisting of age, gender, education, political views, ethics education, work experience, US citizenship, English as primary language, region of origin, and religious practice was requested.

\section{Scoring}

The ESIT responses were scored using the key provided by the School of Public Policy, Georgia Institute of Technology. The ESIT consists of six case studies. Students are asked to choose what they would do and then to rate a list of issues based on their importance in deciding. The rankings are a Likert scale from great to no importance. Then students are asked to rank the top 4 issues they used to make their decision in the order of importance. The issues provided include post-conventional, conventional, pre-conventional, and nonsensical issues.

Responses were rejected if they failed to complete a significant number of questions (equivalent to approximately two case studies), if they rated the nonsense questions too high, or if they ranked multiple items as most important.

A PSCORE was calculated as a ratio of all the post-conventional issues that were ranked in the top 4 to all the issues that were ranked in the top 4. The PSCORE ranges from 0 to 1 , with a higher score showing a more advanced ethical understanding. An N2Score was calculated as PSCORE $-3 *$ (average rating on post-conventional issues - average rating on pre-conventional issues)/standard deviation of ratings on pre- and post- conventional issues.

The numbers of students participating and a selection of demographic data is shown in Table 1 .

Table 1 Selected Demographics by Course

\begin{tabular}{lrrrr} 
& Intro $13-14$ & Intro $14-15$ & ESS 13-14 & ESS 14-15 \\
\hline Number Enrolled & 69 & 62 & 48 & 42 \\
\hline Responses Received & 57 & 50 & 41 & 34 \\
\hline Responses Rejected & 19 & 7 & 5 & 7 \\
\hline Responses Scored & 38 & 43 & 36 & 27 \\
\hline Educational Level & & & & \\
\hline Freshmen & 52 & 42 & 0 & 0 \\
\hline Sophomore & 1 & 6 & 0 & 0 \\
\hline Junior & 2 & 2 & 3 & 3 \\
\hline Senior & 0 & 0 & 37 & 30 \\
\hline No response & 2 & -- & 1 & 1 \\
\hline Mender & & & & 37 \\
\hline Female & 47 & 40 & 3 & 3 \\
\hline No response & 10 & 10 & 4 & -- \\
\hline English & -- & --- & --- & \\
\hline Language other than English & & & & 29 \\
\hline No response & 49 & 41 & 40 & -- \\
\hline Native Language & 7 & 8 & --- & - \\
\hline
\end{tabular}


The usable response rate varied from $55 \%$ to $75 \%$. Note that first test administered had a high number of rejections. Additional instructions were given at later tests to clarify the instructions.

\section{Data Analysis}

The sample size of this study was not large enough to assess the validity of the test. However, differences between the groups were compared to assess the differences in the groups. As an initial step, the variability of the freshmen class in year 1 was compared to the variability of the freshmen class in year 2 and the variability of the senior class in year 1 was compared to the variability of the senior class in year 2 using a two-sample F-test to compare the population variances. The comparison showed no statistically significant variability between years, so the freshmen class data and the senior class data were pooled across the years to produce two data sets.

The P scores and N2 scores of the ESIT exam of the freshmen data was compared to the senior data using a two-sample $t$-test to determine if there are differences in the two groups.

\section{Results}

The data collected are summarized in Table 2. In brief, the PSCORE of Intro Students $(M=0.516)$ was higher than that of Senior Seminar Students $(M=0.487)$; this difference was not statistically significant, $(\mathrm{t}(142)=1.33, \mathrm{p}<0.5)$. The N2Score of Senior Seminar Students $(\mathrm{M}=2.63)$ was higher than that of Intro Students $(\mathrm{M}=2.54)$; this difference was also not statistically significant, $(\mathrm{t}(142)=0.385, \mathrm{p}<0.5)$. Therefore, there was no statistically significant difference between the two groups and there is not sufficient information to accept our hypothesis.

Table 2 PSCORE and N2Score by class and combined

\begin{tabular}{l|r|r|r|r|r}
\hline Class & $\mathrm{N}$ & PSCORE & Variance & N2Score & Variance \\
\hline Intro 13-14 & 38 & 0.515 & 0.021 & 2.508 & 3.028 \\
\hline Intro 14-15 & 43 & 0.517 & 0.017 & 2.569 & 1.958 \\
\hline ESS 13-14 & 36 & 0.497 & 0.014 & 2.789 & 1.559 \\
\hline ESS 14-15 & 27 & 0.474 & 0.015 & 2.432 & 2.187 \\
\hline Intro Combined & 63 & 0.516 & 0.019 & 2.541 & 2.429 \\
\hline ESS Combined & 81 & 0.487 & 0.015 & 2.636 & 1.829
\end{tabular}

\section{Conclusions}

Given the difficulty of measuring ethical understanding, the results should be considered preliminary and indicative only. As shown in Table 3, the scores for the freshmen class compare favorably to those reported after ethics training by Borenstein, et al. ${ }^{4}$ 
Table 3 PSCORE and N2Score comparison with Borenstein, et al.

\begin{tabular}{l|r|r|r}
\hline Class & $\mathrm{N}$ & PSCORE & N2Score \\
\hline Intro Combined & 63 & 0.516 & 2.541 \\
\hline ESS Combined & 81 & 0.487 & 2.636 \\
\hline $\begin{array}{l}\text { All experimental students and control students with reported } \\
\text { ethics experience* }\end{array}$ & 425 & 0.523 & 3.326 \\
\hline
\end{tabular}

* Table 3 (Borenstein, et al., 2009)

However, the results are troubling. If our engineering ethics education is truly effective, we would expect to see an increase in the sophistication of the students' ethical thinking over their time at the university, despite the high level of the freshmen scores. This study implies that students in our program are not improving their knowledge of engineering ethics. Based on this study, it seems that the School of Engineering should consider curriculum changes to improve our teaching of engineering ethics.

\section{Further Research}

This study is preliminary only, so it should be continued to provide more information that can be used to revise teaching of engineering ethics. In the School of Engineering, this study should be continued each year so that longitudinal data can be assessed to determine if individual students are learning through their time at the University. This study could be complemented with a qualitative study examining the sources of student's ethical thinking and reasoning. This could assist the School of Engineering in examining and potentially revising their engineering ethics training. An expansion of this study to multiple institutions would provide valuable comparative data. Although this study shows no significant difference between freshmen and seniors, we have only limited data to determine how our students compare to those in other institutions.

The data from this study will be provided to Borenstein, et al., to assist in further validation and improvement of the ESIT.

As the ability of engineers to impact our world grows, the importance of engineering ethics grows as well. Continued research in this area is key to ensure that engineering faculty are able to provide our students with the ability to meet the challenges they will face.

\section{Acknowledgments}

This study would not have been possible without the generous permission of Jason Borenstein and his team at the School of Public Policy, Georgia Institute of Technology to use their ESIT. I also would like to thank Dr. Robert Egbert who oversaw the study design, the Walla Walla University Ethics in Research Committee for their feedback on the study design, all the students who participated, and the ASEE reviewers and Debbie Muthersbaugh who provided helpful comments on the draft paper. 


\section{References}

1. ABET. (2012) Criteria for accrediting engineering programs. www.abet.org

2. Barry, B. E., \& Ohland, M. W. (2012). ABET Criterion 3.f: How Much Curriculum Content is Enough? Science \& Engineering Ethics, 18, 369-392. doi:10.1007/s11948-011-9255-5

3. Shuman, L.J., Besterfield-Sacre, M., \& McGourty, J. (2005) The ABET "professional skills"- can they be taught? Can they be assessed? Journal of Engineering Education, 94, 41-55. doi: 10.1002/j.21689830.2005.tb00828.x

4. Barry, B. E., \& Ohland, M.W. (2009) Applied ethics in the engineering, health, business, and law professions: A comparison. Journal of Engineering Education, 98, 377-388. doi: 10.1002/j.2168-9830.2009.tb01034.x

5. Stephan, K.D. (1999) A survey of ethics-related instruction in U.S. engineering programs. Journal of Engineering Education, 88, 459-464. doi: 10.1002/j.2168-9830.1999.tb00474.x

6. Pfatteicher, S. K.A. (2001). Teaching vs. preaching: EC2000 and the engineering ethics dilemma. Journal of Engineering Education, 90, 137-142. doi: 10.1002/j.2168-9830.2001.tb00581.x

7. Davis, M., \& Feinerman, A. (2012). Assessing graduate student progress in engineering ethics. Science \& Engineering Ethics, 18, 351-367. doi:10.1007/s11948-010-9250-2

8. Colby, A., \& Sullivan, W. (2008) Ethics teaching in undergraduate engineering education. Journal of Engineering Education, 97, 327-338. doi: 10.1002/j.2168-9830.2008.tb00982.x

9. Chang, P., \& Wang, D. (2011). Cultivating engineering ethics and critical thinking: A systematic and crosscultural education approach using problem-based learning. European Journal of Engineering Education, 36, 377-390. doi: 10.1080/03043797.2011.596928

10. Bero, B., \& Kuhlman, A. (2011) Teaching ethics to engineers: Ethical decision making parallels the engineering design process. Science \& Engineering Ethics, 17, 597-605. doi: 10.1007/s11948-010-9213-7

11. Shuman, L.J., Sindelar, M.F., Besterfield-Sacre, M., Wolfe, H., \& Pinkus, R.L. (2004) Can our students recognize and resolve ethical dilemmas? Proceedings of the 2004 American Society for Engineering Education Annual Conference \& Exposition. Session Number 1526

12. Abaté, C.J. (2011) Should engineering ethics be taught? Science and Engineering Ethics , 17, 583-596. doi: 10.1007/s11948-010-9211-9.

13. Li, J., \& Fu, S. (2012). A systematic approach to engineering ethics education. Science \& Engineering Ethics, 18, 339-349. doi: 10.1007/s11948-010-9249-8

14. Jonassen, D. H., Shen, D., Marra, R. M., Young-Hoan, C., Lo, J. L., \& Lohani, V. K. (2009). Engaging and supporting problem solving in engineering ethics. Journal of Engineering Education, 98, 235-254. doi: 10.1002/j.2168-9830.2009.tb01022.x

15. Sindelar, M.F., Shuman, L.J., Besterfield-Sacre, M., Miller, R., Mitcham, C., Olds, B., Pinkus, R., \& Wolfe, H. (2003) Assessing engineering students' abilities to resolve ethical dilemmas. $33^{\text {rd }}$ ASEE/IEEE Frontiers in Education Conference Session S2A p 25-31

16. Borenstein, J., Drake, M. J., Kirkman, R., \& Swann, J. L. (2010). The Engineering and Science Issues Test (ESIT): A discipline-specific approach to assessing moral judgment. Science \& Engineering Ethics, 16, 387407. doi: $10.1007 / \mathrm{s} 11948-009-9148-\mathrm{z}$ 